\title{
Unilateral exophthalmus in an acute episode of MS
}

\section{Brodoehl $\mathrm{S}^{1,2^{*}}$, Liebermann $\mathrm{J}^{2}$, Herfurth $\mathrm{J}^{2}$ and Lobenstein $\mathrm{S}^{2}$}

${ }^{1}$ Department of Neurology, University Hospital Jena, Germany

${ }^{2}$ Department of Neurology, Naumburg, Germany

Here we present a clinical case of a unilateral exophthalmus which occurred for the first time in an acute episode of multiple sclerosis (MS). Diplopia occurred together with a new paresis of the left hand. Concerning the paresis of the hand, a cervical spinal lesion was found, whereas the cause of the diplopia is most likely a protrusion of the right

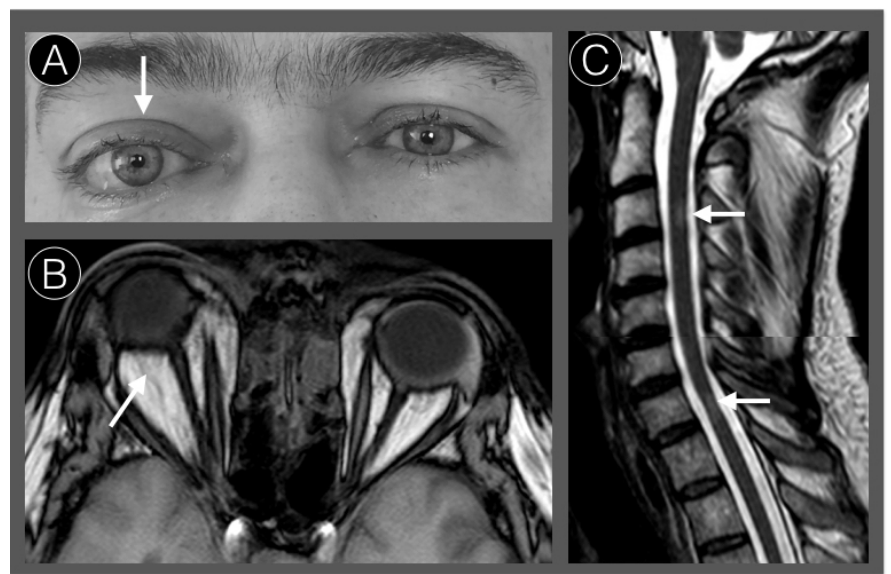

Figure 1. Exophthalmus in an acute MS episode. (A) Clinical presentation of exophthalmusof the right eye (arrow) and diplopia. (B) Transversal T2-weighted MRI with protrusion of the right eye and proliferation of intra-orbital fat tissue (Comerci, Elefante et al. 2013). (C) Sagittal T2-weighted MRI with two spinal lesions (arrows), the lesion in the upper cervical spine ( $\mathrm{C} 3$, upper arrow) showed gadolinium enhancement and was most likely the reason for the acute paresis of the left hand. eye. Diplopia improved slightly under a cortisone regime. Laboratory study and thyroid ultrasonography did not reveal an endocrine cause of the exophthalmus and the physiological relationship to MS remained elusive. However, a type of autoimmune-overlap syndrome must be considered [1-3].

\section{References}

1. Comerci M, Elefante A, Strianese D, Senese R, Bonavolonta P, et al. (2013) Semiautomatic regional segmentation to measure orbital fat volumes in thyroidassociated ophthalmopathy. A validation study. Neuroradiol J 26: 373-379. [Crossref]

2. Marrie RA, Reider N, Cohen J, Stuve O, Sorensen PS, et al. (2015) A systematic review of the incidence and prevalence of autoimmune disease in multiple sclerosis. Mult Scler 21: 282-293. [Crossref]

3. Niederwieser G, Buchinger W, Bonelli RM, Berghold A, Reisecker F, et al. (2003) Prevalence of autoimmune thyroiditis and non-immune thyroid disease in multiple sclerosis. J Neurol 250: 672-675.[Crossref]
Correspondence to: Brodoehl Stefan M.D., Department of Neurology, University Hospital Jena, Germany, E-mail: stefan.brodoehl@med.uni-jena.de

Received: August 09, 2016; Accepted: September 13, 2016; Published: September 16, 2016 